\title{
CURRÍCULOS, ESTÉTICA E A NORMA DO CANCELAMENTO
}

\author{
Virgínia Maria Barcellos ${ }^{1}$ \\ Wenderson Silva Oliveira ${ }^{2}$
}

\section{RESUMO}

Utilizando o episódio acerca da crítica que Lilia Schwarcz fez ao trabalho mais recente da cantora Beyoncé, o texto pretende, dentro do campo teórico pós-estrutural, afrouxar perspectivas à leitura do ocorrido, estendendo o debate para o campo do currículo no Brasil. Ao final, sugerimos que rastros da essencialização ocidental prejudicam um entendimento mais amplo da questão e nos questionamos se são possíveis outros tipos de estar no mundo.

PALAVRAS-CHAVE: cultura do cancelamento. currículo. BNCC.

\section{ABSTRACT}

Using the episode about Lilia Schwarcz's criticism of singer Beyoncé's most recent work, the text intends, within the post-structural theoretical field, to loosen perspectives on the reading of what happened, extending the debate to the field of curriculum in Brazil. In the end, we suggest that traces of Western essentialization hinder a broader understanding of the issue and we ask ourselves whether other types of being in the world are possible.

KEYWORDS: cancel culture. curriculum. BNCC.

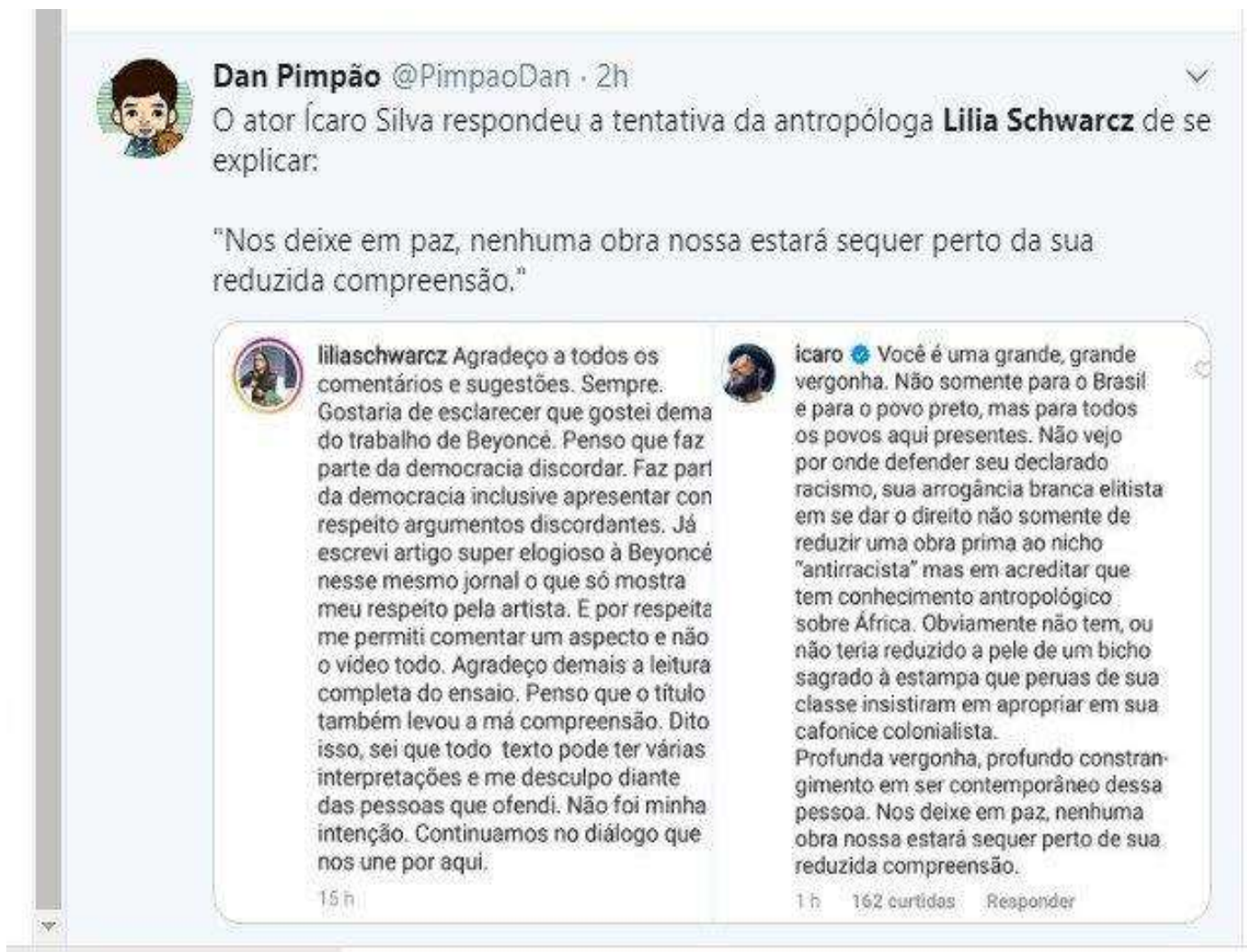

Resposta do ator Ícaro Silva após publicação da coluna sobre o filme Black is King de Beyoncé, de assinatura da antropóloga Lilia Schwarcz ${ }^{3}$

\footnotetext{
1 ISAT / ProPEd UERJ

2 Doutorando em Educação - UECE

${ }^{3}$ Disponível em: <https://www.metropoles.com/entretenimento/cinema/historiadora-lilia-schwarcz-e-canceladapor-criticas-a-beyonce-entenda> . Acesso em: 3 fev. 2021.
} 
Em julho de 2020 os estúdios Disney lança o filme Black is King dirigido pela multiartista Beyoncé. Nele, a cantora e compositora combina duas histórias clássicas Hamlet e O Rei Leão. No entanto, o ambienta em algum lugar não explicitado do continente africano, se utilizando de uma estética rica e glamorosa. Dias depois, a antropóloga e professora Lilia Moritz Schwarcz escreve para a coluna opinião do jornal Folha de S. Paulo:

\begin{abstract}
A loucura é a alienação de dar as costas ao passado. A traição remete àqueles que procuraram omitir o orgulho diante da ancestralidade africana. Em vez do esquecimento, melhor é começar a história outra vez, a partir daquilo que foi pretensamente apagado pelo trauma colonial, mas continua pulsando vivo à espera do seu resgate... Nesse contexto politizado e racializado do Black Lives Matter, e de movimentos como o Decolonize This Place, que não aceitam mais o sentido único e Ocidental da história, duvido que jovens se reconheçam no lado didático dessa história de retorno a um mundo encantado e glamorizado, com muito figurino de oncinha e leopardo, brilho e cristal... Quem sabe seja hora de Beyoncé sair um pouco da sua sala de jantar e deixar a história começar outra vez, e em outro sentido ${ }^{4}$.
\end{abstract}

Imediatamente após a publicação, Schwarcz foi acusada pela opinião pública de racismo. Várias/os internautas fizeram postagens a respeito de uma suposta interpretação equivocada da antropóloga acerca da performance vídeo-musical de Beyoncé. Os discursos, dos mais variados possíveis, giravam em torno da racialização de Schwarcz versus a racialização de Beyoncé. Dessa problemática, surgiram diversas opiniões de pessoas negras respondendo a publicação na rede social Instagram, as quais, em grande parte, apresentavam críticas severas ao texto de Lília, que, faz-se necessário ressaltar, é restrito a assinantes da Folha. A imagem da abertura desse texto é do ator Ícaro Silva em resposta à postagem inicial, do outro lado, Lília rebate os comentários em outra postagem em sua conta pessoal. Mas, já era tarde demais, Lília já havia sido "cancelada".

A cultura do "cancelamento" diz respeito a atitudes dentro de uma comunidade que pedem ou provocam a interrupção do apoio a atores, políticos, músicos, influenciadores digitais ou qualquer outra figura pública, geralmente em resposta a algum tipo de postura considerada condenável, ofensiva ou preconceituosa. "Cancelar" uma pessoa tornou-se uma prática usada por muitas/os pessoas nas redes sociais nos últimos anos, e foi eleito como 'o termo do ano' em 2019 pelo Dicionário Macquarie, que todos os anos seleciona as palavras e expressões que mais caracterizam o comportamento de um ser humano. Neste escrito, não buscamos fazer juízo de valor sobre o acontecimento, mas, dentro de uma perspectiva pósestruturalista, fazer um convite à reflexão sobre dois pontos: 1) Sobre o jogo entre o tempo e

\footnotetext{
4 Disponível em: <https://www1.folha.uol.com.br/ilustrada/2020/08/filme-de-beyonce-erra-ao-glamorizar-
} negritude-com-estampa-de-oncinha.shtml>. Acesso em: 3 fev. 2021. 
as perspectivas (HARAWAY, 1995); 2) A teoria anteriormente criada nos permite ver o mundo como opera hoje? O que nos dificulta ver o que Beyocé faz, são as normas que nela operam, ou a teoria que usamos?

Não é a primeira vez que a cantora está no centro de uma análise teórica. Em seu artigo Manifesto Beyoncé no currículo: a força da música e o brilho erótico do corpo que dança Thiago Ranniery explica:

\begin{abstract}
Quando recorro a composição manifesto Beyoncé, aludo ao sentido duplo de manifesto para o qual aponta Azevedo (2012, p. 48), de que "passa a significar não somente o que pode se tornar "visível pela tradução em palavras, mas também o que serve para carregar os sentimentos, ideias, impulsos[...], aquilo que não pode mais permanecer oculto e dissimulado em sua natureza”. Não se trata exatamente de um chamado à luta, mas de explicitação, de aparecimento, de emergência à luz (RANNIERY, 2018, p. 200).
\end{abstract}

Algumas coisas precisam vir à luz, mesmo que machuque os olhos sensíveis de quem não está acostumado a olhar para ela. Há determinadas armadilhas do poder que funcionam silenciosamente por meio das inúmeras vigilâncias, um tipo de panoptismo (FOUCAULT, 2014) capaz dos mais efetivos controles de nossos processos de subjetivação. Por isso, nossa atenção se volta a esses processos, às operações da norma por meio do que se pode chamar de "cultura do cancelamento". Essas práticas desacreditam todo discurso proferido, que passa a ser entendido como "falhado" (PELÚCIO; DUQUE, 2020), operações normativas que ditam, de modo parcial, quem tem ou não legitimidade para falar sobre um determinado assunto, que mantém forte ligação, sobretudo, com as identidades, forjadas por meio desses mesmos discursos normativos.

Sabemos que a glamourização da cultura ocidental branca pela indústria do audiovisual já é um fato reconhecido (MBEMBE, 2019; PEREIRA, 2019). São inúmeras obras onde operam projetos complexos: a supremacia da cultura branca, criminalização da pobreza, uma sociedade do espetáculo ${ }^{5}$ onde esse se dá como o conjunto das relações sociais mediadas pelas imagens. Voltando ao texto, esse revela um incômodo com o glamour. As representações hollywoodianas dos palácios europeus dos séculos XVI, XVII e XVIII são igualmente glamourizados e longe da realidade histórica que conhecemos. Não há dente podre, menção aos odores de gente que não tomava banho e as demais práticas de higiene que hoje seriam consideradas um total absurdo entre os vikings romantizados do cinema. Nas telas, por várias vezes, Henrique VIII parecia um Dom Juan.

${ }^{5}$ (DEBORD, 2013). 
Há um discurso enunciado e reiterado constantemente para ser afirmado como verdadeiro que coloca homens brancos como conquistadores maravilhosos. Tanto que veremos nas narrativas que Iracema, Pocahontas e Malinche não foram violentadas, elas se apaixonaram pela luminosidade irresistível da branquitude. A branquitude construiu para si um passado como uma fábula insana e absolutamente irreal onde temos diversos modelos a seguir. A prática artística ocidental cria narrativas de forma heroica (não podemos esquecer o Renascimento) uma recriação mítica de um passado romantizado e idealizado.

Mas por que cobrar de Beyoncé algo que nunca é cobrado das produções da branquitude? Por que não considerar como esse tipo de estratégia pode afetar positivamente pessoas que tiveram seu passado sequestrado e até hoje são inferiorizadas e caçadas pela polícia? Vemos Black is King como um ebó ${ }^{6}$ de autoestima. Capitalista sim, mas capitalista é o ocidente em que vivemos. Pretender que uma artista da indústria musical no coração do capitalismo produza algo que problematize o sistema político vigente é inocente. Não é renegar rótulos para não reforçar efeitos de manutenção; Um descolonial que pretende discutir algo de fora das relações de poder, como se isso fosse possível, pois não é. Não podemos esquecer que no lugar de abjeção tem vida. E talvez seja saudável recusar o rótulo batido de só sofrimento. Questionar a norma não é viver fora dela. É viver nela, questionando. A subjetividade como agência, mesmo que essa subjetividade produza efeitos incontroláveis.

Acreditamos que, vivendo dentro da norma, questionando seus discursos e efeitos, os corpos, no momento em que se posicionam em aliança, "estão reivindicando o direito de aparecer, de exercitar a liberdade, e estão reivindicando uma vida que possa ser vivida" (BUTLER, 2018, p.33). O que estaria Beyoncé desejando provocar ao subverter a Aesthesis em voga? Modos diferentes de habitar a normatividade? Estaríamos vendo uma luta política pela significação? Segundo Viveiros de Castro (2011) existem devires diferentes. O devir no autor referido é imanente, ou seja, o que move o ser é o desejo. Um devir-outro que nos movimenta pelo medo do que está por vir. Eu o desejo, mas não tenho controle sobre ele. Eu desejo esse medo, entretanto eu sofro a ação do outro que quer me incluir nele.

Butler quando discute a "analítica do poder" explica:

Minha opinião é a de que tem sido um erro considerar que algumas vidas são mais
reais, mais vivas que outras, que seriam menos reais, menos vivas. É uma forma de
descrever e de avaliar a distribuição diferencial da "realidade" em função do nível
de conformidade dessas populações referente às normas estabelecidas. É também
uma tentativa de produzir novos esquemas normativos que implicam uma crítica
rigorosa da misoginia, da homofobia, do racismo para fazer emergir um mundo

\footnotetext{
${ }^{6}$ Uma oferenda típica nas religiões afro-brasileiras onde os praticantes se desfazem de um bem material em
} homenagem a um orixá ou entidade espiritual. 
social e político que se caracterizaria pela interdependência, igualdade e mesmo pela democracia radical (BUTLER apud PAGÈS, 2013, p. 6).

A autora tenta demonstrar uma ambivalência no coração da normatividade. Segundo Butler, a performatividade é uma análise do poder. Porém há algo de fracasso na repetição. Constrangimentos. Não é porque a norma não é determinadora que tudo é permitido. "Temos um quadro normativo que busca contestar e substituir a distinção propriamente dita do real e irreal" (BUTLER apud PAGÈS, 2013, p. 5). Se o poder pode se exercer pelo conhecimento, se o conhecimento pode operar na Aesthesis perpetuando assim um CIStema ${ }^{7}$, um quadro normativo que dita o real e irreal, uma relação performática daquilo que o Estado quer ouvir, talvez seja hora de fazer estranha a nossa forma de enxergar, para poder enxergar.

Entendemos que o capitalismo é a raiz de quase todos os problemas da desigualdade social, mas por que não usar parte do veneno para criar uma vacina? A artista em questão veio do seio cristão texano, e está igualmente em processo de descolonização do próprio imaginário. Em seu filme ela diz "a vida é uma jornada”. Criar uma saga de um herói preto, colocar referências dos Orixás do início ao fim da obra é absolutamente corajoso e ousado em um país em que a cultura negra está há séculos vinculada às igrejas protestantes. Se isso não é um ato de descolonização poderoso, ficamos perplexos.

A antropologia, campo de estudo da professora Schwarcz 'ainda é muito dona do Negro' e suas narrativas. Isso pode ter influenciado fortemente a opinião pública a incitar o seu cancelamento, como se essa narrativa provocasse o seu cancelamento real e não somente dentro das redes sociais. A autora supor que fazer dos pretos reis e rainhas poderia criar um imaginário de $u$ bermensch ${ }^{8}$, é uma mostra clara da incapacidade de perceber um trabalho de arte para além dos instrumentos da filosofia ocidental. O que é a iniciação do candomblé, por exemplo, além da possibilidade de nos tornarmos parte do corpo dos Deuses? A lógica da Beyoncé pode não estar longe disso, e sim ser uma tentativa de engendrar autoestima no imaginário de uma população que é violentada há mais de quatro séculos.

Existe um provérbio Nagô que diz "O tempo não gosta do que se faz sem ele" (SODRÉ, 2017). Entendemos as críticas realizadas à coluna e não ignorando os muitos elogios que Schwarcz tece à Beyoncé no mesmo texto, imaginamos outra interpretação, inspirada nas teorias suturantes, que não identificamos em outros escritos que se propuseram a analisar o ocorrido até então. Nesse novo ambiente, a professora, imersa em temporalidades

\footnotetext{
7 Essa terminologia tem sido utilizada por Sara York (2020), para identificar a norma da cisgeneridade pesando compulsoriamente sobre os sistemas de gênero.

${ }^{8}$ As duas traduções mais comuns para Übermensch são super-homem e além-do-homem. Nenhuma delas é perfeita, mas as duas trazem a ideia de superação, de alguém que se eleva, a criação de um novo tipo.
} 
essencializantes, exige que a cantora siga reproduzindo suturas que essa imagina, pode chegar a algum tipo de resultado esperado, através da reprodução de normas de reconhecimento e homenagem a uma ancestralidade. Beyoncé, em um movimento de devir-outro, não quer mais controlar as consequências, repetir-se, mas respirar uma trama de significantes onde os sentidos são atribuídos, e viver a poesis para perceber as coisas em outra perspectiva. Sob esse ponto de vista, a discussão aqui não seria sobre racismo, mas sobre quanto cada uma delas está disposta a deslocar suturas tão violentamente imbricadas, investindo em novos sentidos (LOPES, 2016). Talvez a ação de cada uma reflita o segundo ponto a que me referi no terceiro parágrafo desse texto: Será que a teoria anteriormente criada nos permite ver o mundo como opera hoje, ou ela não entregar aquilo que promete?

Toda a discussão Queer é uma crítica às políticas de identidade (MISKOLCI, 2009). Dito isso, Queer não é uma identidade, mas um modo de fazer política. No caso acima discutido, não seria Beyoncé imersa em uma performance queer, deslocada da indústria cultural em que ela se insere como profissional? "Um Eu que é radicalmente Outro. Um animismo alterado pela alteridade" (VIVEIROS DE CASTRO, 2011, p. 911). O jogo de Beyoncé tem a ver com tradução. Tradução como alteridade. Não tem falha, são camadas, suturas ou o afrouxamento dessas. Enxergar através dessas camadas é o segredo. Como traduzir a Poesis de Black is King dentro dessa indústria? Qual signo o CIStema compreende? Como tentar produzir suturas que sejam menos suturantes, trabalhos que engendram parâmetros estéticos/estétnicos os quais a mentalidade branca nas artes de forma geral não dá conta? As ações da branquitude em limitar suas avaliações, é fruto de uma pane cognitivoafetiva-sensível (DEWEY, 2010).

Talvez o queer nos ajude a pensar sobre a tradução que Beyoncé realiza. O queer enfrenta políticas de identificação, desidentificando ao identificar. Nesse aspecto, interroga o discurso que torna a imagética negra abjeta. E nisso, a política queer, impulsionada por Beyoncé impulsiona "uma analítica da normalização que pode interrogar como as fronteiras da diferença são constituídas, mantidas ou dissipadas" (MISKOLCI, 2009, p.178). Mas, como leitoras do queer, interrogamos a interrogação da artista. Na política de desidentificação, não estaria, portanto, Beyoncé performando uma identidade que constrói uma estética, ao invés de entender essa identidade como cambiante e em contínuo processo? É nesse sentido, provavelmente com outros objetivos que fogem aos limites de nossas palavras neste trabalho, que Lília Schwarcz caminha, no sentido de des-identificar as operações normativas que a construção da identidade (em berços capitalistas) oferece.

Nesse sentido, devemos nos lembrar que 
[...] as identidades são construídas dentro e não fora do discurso que nós precisamos compreendê-las como produzidas em locais históricos e institucionais específicos, no interior de formações e práticas discursivas específicas, por estratégias e iniciativas específicas. Além disso, elas emergem no interior do jogo de modalidades específicas de poder e são, assim, mais o produto da marcação da diferença e da exclusão do que o signo de uma unidade idêntica, naturalmente constituída, de uma "identidade" em seu significado tradicional - isto é, uma mesmidade que tudo inclui, uma identidade sem costuras, inteiriça, sem diferenciação interna (HALL, 2014, p. 109-110).

O "cancelamento" à Lília Schwarcz, dentre outras linhas, parte da política de identificação de uma identidade que é supostamente fixada por meio de discursos enunciativos que polarizam um binarismo: preto-branco, hétero-homo, cis-trans e por aí vai... Práticas, como já dissemos, vigilantes, mas não uma vigilância qualquer, é uma vigilância normativa, utilizada pelos jogos de força do poder para promover uma inquietação em quem desliza da norma que se coloca nessas práticas discursivas. Dizemos isso não com o intuito de menosprezar pautas identitárias e políticas de identificação, pelo contrário, reconhecemos a importância delas para que os direitos político-sociais sejam garantidos e mantidos, entretanto, não podemos deixar de mencionar que a política de cancelamento é uma armadilha eficaz do poder, nesse caso, reforça essa polaridade binária, que é responsável por desautorizar falas que possam interrogar o entrincheiramento identitário, como menciona Larrisa Pelúcio (2020).

Mas, em que isso se liga aos currículos? Vivemos um momento histórico onde o currículo pula definitivamente os muros da escola e entra na casa das pessoas. Currículo, Arte e Cultura são consumidos através dos mesmos aparatos midiáticos. A aula online dada pela professora da escola e Black is King são emitidos, absorvidos e processados pelos mesmos canais, se é que algum dia isso se deu de forma distinta. Existe um fim para a arte? Existe um fim para a escola (MACEDO, 2011; 2017)? Se aqui sugerimos olharmos a teoria e a Arte com novos olhos, sugerimos também olharmos pra escola com estranhamento, entendendo que tem coisas lá que não consigo ver, reconhecendo a nossa incapacidade de enxergar o que lá está, fruto de uma teorização criada para guiar o meu olhar. A utilidade da teoria é o teorizar (YOUNG, 2000) e a da desconstrução teórica é mostrar as promessas não entregues, um certo inquietamento teórico que não clama a criação de uma nova teoria para colocar no lugar da anterior (SILVA, 1999), mas a exploração de um "pode ser que...". Não vemos a produção do corpo na escola porque usamos uma teoria que não facilita isso.

Afrouxamentos, deslizamentos, deslocamentos ou qualquer outra ideia que nos permita entender que mesmo a normatividade sendo a totalidade do ser, que o poder é um conjunto de relações em potência, pode-se e deve-se mudar de ideia ao longo do tempo. Como diz Viveiros de Castro (2011, p. 911) “Se a fronteira é, de várias maneiras, o lugar do perigo e do medo por 
excelência, está claro hoje que o mundo contemporâneo pode ser tudo, menos um mundo sem fronteiras." Fronteiras não serão eliminadas, mas ao cruzarmos ou mesmo ao encurtarmos as distâncias, uma politica- arte da convivência será possível. E para além, uma política-arte de aliança entre corpos (BUTLER 2018).

Larissa Pelúcio e Thiago Duque (2020) nos chamam atenção para o "cancelamento" que é promovido e vivificado nas práticas alinhadas aos grupos ultradireitistas e conservadores no Brasil, sobretudo com a ascensão partidária de Jair Bolsonaro à Presidência da República. A autora inicia a discussão partindo do discurso de posse de Bolsonaro como presidente, no ano de 2019, no qual afirma veemente que inaugura-se uma nova fase no Brasil, o fim do politicamente correto. Ora, quem vem sofrendo com essa prática, em um era da pós-verdade irmã gêmea do "cancelamento" -, são as discussões educacionais, sobretudo os currículos. Diznos Pelúcio e Duque (2020, p.137): “As redes sociais digitais ovacionadas pelos(as) entusiastas do governo de Bolsonaro serviram também de palco para linchamentos, silenciamentos, apagamentos e "cancelamentos" de possíveis parceiras(os) e aliados(as)".

Os discursos de ódio se transfiguram nos "cancelamentos" e pesam sobre os corpos precarizados por essa política de diversas formas. Embora não escolha lados, lembremos que Lília Schwarcz é branca, mas é uma mulher, também sua vivibilidade é afetada por esses mesmos discursos. Os tribunais das redes sociais, insuflados por esses discursos acabam por deslegitimar as falas que se contrapõem às políticas de identificação, como no caso dos bolsonaristas, uma vez que "cancelam" quaisquer pessoas que se levantam contra suas operações, mesmo aliadas/os políticos. "Cancelam" e são responsáveis por outros “cancelamentos", o que nos faz lembrar o episódio ocorrido no ano de 2011, no qual, houve a produção do material da campanha Escola sem Homofobia. Na ocasião, por uma notícia falsa espalhada por Bolsonaro ao intitular o material como kit gay, Dilma Rousseff resolveu "cancelar" - literalmente - a distribuição do material nas escolas e os movimentos sociais envolvidos em sua produção. Desse modo, essa política normativa de "cancelamento" não somente perpassa as relações virtuais como começa a valer-se delas para promover um pânico moral (COHEN, 2002) fora dessa virtualidade.

Apontar para os efeitos da norma do "cancelamento" é tentar friccioar, dentro do jogo do poder, um projeto de descolonização epistemológica (ALCOFF, 2016). Mostrando não somente as problemáticas das identidades fixas forjadas nos projetos de poder colonialistas, mas os silenciamentos e desautorizações que outras formas de identificação recebem quando interrogam esses modelos. Linda Alcoff nos propõe que pensar esse projeto "presume a importância epistêmica da identidade porque entende que experiências em diferentes 
localizações são distintas e que a localização importa para o conhecimento" (ALCOFF, 2016, p.136). A identidade que a autora levanta não diz respeito à rigidez e fixação de lugares e estereotipias, mas sim, à luta coletiva, uma política de alianças (BUTLER, 2018) que tornam a vida dos sujeitos precários mais fruível, vivível. Não somente a vida como sua produção estética.

Lembremo-nos de outro caso de "cancelamento". No ano de 2017, Wagner Schwartz realizou uma performance no Museu de Arte Moderna de São Paulo, chamada La Bête (O Bicho). Segundo reportagem do jornal El País ${ }^{9}$, o artista havia se apresentado mais de dez vezes essa performance no Brasil e na Europa. A performance prevê a participação de espectadores, numa interação com a obra apresentada, na ocasião, havia uma criança acompanhada por sua mãe. A partir de uma filmagem clandestina na qual mostra a criança tocando um dos pés de Schwartz, há um verdadeiro linchamento virtual ao artista, por parte de políticos, alguns outros artistas, igrejas cristãs e outras pessoas anônimas espalhadas pelo Brasil.

O Ministério Público de São Paulo abriu um inquérito para apurar o suposto caso de pedofilia, assim como o Senado Federal instaurou uma CPI para caçar a bruxa pedófila que estava solta. As milícias do ódio, por meio da operação do "cancelamento" fez valer no tribunal da internet a punição para Wagner Schwartz. A partir daí, várias bruxas soltas pelo país que usavam seus corpos como meios para pensar e fazer arte foram expostas nesses tribunais. Intensifica-se uma deslegitimação com sujeitos acadêmicos, artistas não-populares e pessoas que defendem pautas progressistas que questionam a norma. O certo e errado, como efeitos de verdade, passaram a servir de balança para "cancelar". E por meio disso que os indivíduos "cancelados" são forçados a se redimirem, para que se prevaleça a verdade, a moral e os bons costumes. A norma, a lei.

Mas, essa política de "cancelamento" não tem sido aplicada a todas as pessoas com a mesma severidade. Os tribunais da internet (e fora dela) selecionam bem e essas ações seletivas têm deixado de pesar nos corpos que ocupam cargos políticos, como a Ministra Damares Alves, que afirmou em sua posse que meninos vestem azul e meninas vestem rosa. Isso para não dizer das outras vezes em que a Ministra sufoca pautas de violência contra as mulheres ou quando a Ministra tentou intervir no aborto de uma criança de dez anos, vítima de estupro. Por outro lado, alguns esquerdistas também sufocam as pautas que reivindicam direitos de existência, como as pautas LGBT, as pautas raciais e os feminismos. Ou seja, a ativação do "cancelamento" ocorre em meio às identificações normativas e o que ameace a norma é colocado na posição de ser

\footnotetext{
${ }^{9}$ Disponível em: $<$ https://brasil.elpais.com/brasil/2018/02/12/opinion/1518444964_080093.html>. Acesso em: 6 fev. 2021.
} 
disciplinarizado. Se por um lado há um grupo ultradireitista conservador que esmaga as pautas que incidem sobre outras identidades que interrogam a norma, por outro há um grupo na esquerda que, de um modo ou outro, "cancela" as identidades que interrogam a norma, em função de uma identidade fixa. Dentro das nossas análises, não sabemos precisar se essa diferenciação de aplicabilidade se dá devido ao gênero da pessoa "cancelada", pela intimidade que grupos de extrema direita tem com as ferramentas e tecnologias utilizadas para tal evento como desenhado no documentário Privacidade Hackeada (2019) ou as duas coisas.

A imbricação acima mostra que temos muitos anos de simplificação, diminuição entre outras coisas. Tudo para ser deslocado, afrouxado (DERRIDA, 2003) precisa de perspectivas distintas. Sob a luz do pós-estruturalismo, consideramos que todas as narrativas são inventadas, frutos de perspectivas cabendo só a quem cria vivê-las ou não. Que fatos são somente perspectivas, relações de poder imbricadas com outras relações de poder. Que ao escolhermos uma perspectiva reforçamos certas normas, abandonando outras possibilidades e vice-versa. Sendo assim, ao invés do professor perseguir os fatos como algo que determina certos e errados (YOUNG, 2000) fosse mais interessante criar ambientes onde os alunos possam refletir sobre as imbricações dessas relações de poder, para entender as consequências e desdobramentos das suas apostas. O pós-estruturalismo pode trazer para o currículo a possibilidade de uma escuta disponível e sincera. A pessoa não escolhe acreditar em algo simplesmente. Isso se dá por uma complexa interpelação de jogos de poder, onde inclui-se a invisibilidade. Pessoas fazem escolhas por que não são vistas ou talvez por que nunca tiveram a oportunidade de conversar sobre as normas que nela operam.

Seria assim o professor um ouvidor? Seria o papel da escola não reforçar certas leis, "cancelamentos", mas o de promover a escuta para a diferença? Não determinar uma consciência, algo que falta ao outro, mas estar ali para receber o outro, para poder receber o outro enquanto o outro, não um outro presumido (DERRIDA, 2003)? Afinal, já entendemos que o real não é real. O real é a escuta. Ou a irrealização dela. O exercício da escuta é a única coisa real.

Os currículos normativos e oficiais operam, silenciosamente, a norma do “cancelamento", selecionam os saberes que devem ficar e os que devem sair dos currículos. Mas, não são quaisquer saberes que ficam, pelo contrário, há uma seletividade que identifica quais corpos estarão nos currículos prescritos, que institui como essencial uma identidade curricular, em detrimento das outras tantas existentes pelo Brasil. Assim, "cancela" aquelas e aqueles estranhos que interrogam as políticas oficiais, instituindo os lugares que essas pessoas deverão ocupar nesse jogo de poder, do lado de fora de determinados discursos. Por isso, ao 
evocarmos o queer como aliança, o fazemos porque acreditamos "justamente por ser, desde sua gênese, um campo de produção intelectual que articula coletiva e criativamente o enfrentamento às domesticações das agendas políticas e intelectuais” (PELÚCIO; DUQUE, 2020, p.147).

A Base Nacional Comum Curricular "cancela", por exemplo, as discussões sobre corpo, gênero e sexualidade em seu texto oficial, instituindo o silenciamento a determinadas pautas que convocam para o debate outras identidades, responsáveis pelo questionamento da identidade cisgênero e heterossexual. Diz-nos Linda Alcoff "que precisamos hoje reinvocar aquele "nós" que incluiria todos os grupos que são alvo de formas de opressão baseadas na identidade" (ALCOFF, 2016, p.142). Por isso, as políticas de aliança que estabelecemos são importantes para que consigamos estabelecer pontes de resistência ao poder, já que aprendemos com Michel Foucault que onde há poder, há resistência.

Retornando ao filme, gostamos da possibilidade de se pensar, exercer e realizar o poder sem a necessidade da construção de uma narrativa que envolva a realeza. Mas isso é um lugar existencial que não entendo ainda como se alcança coletivamente dentro desse espaço-tempo em que vivemos, onde todos estamos correndo atrás de um trono, de um modo ou outro. Nem reforçar normas, nem cancelar. Quem sabe seja hora de apagarmos os rastros da essencialização ocidental, sair um pouco da sala de jantar e deixar a história começar outra vez, e em outro sentido.

\section{REFERÊNCIAS BIBLIOGRÁFICAS}

ALCOFF, Linda. Uma epistemologia para a próxima revolução. Revista Sociedade e Estado, v. 31, n. 1, jan.-abr., 2016.

Black is King. Direção: Beyoncé, Disney Pictures, Estados Unidos, 2020.

BUTLER, Judith. Corpos em Aliança e a política das ruas: notas para uma teoria performativa de assembleia. 2. ed. Rio de Janeiro: Civilização Brasileira, 2018.

COHEN, Stanley. Folk Devils and Moral Panics: The Creation of the Mods and Rockers. 3. ed. Londres: 2002.

DEBORD, Guy. A sociedade do espetáculo. 2003. Disponível em $<$ https://www.marxists.org/portugues/debord/1967/11/sociedade.pdf $>$. Acesso em: 30 jul. 2020.

DERRIDA, Jacques. Anne Dufourmanelle convida Jacques Derrida a falar da Hospitalidade/Jacques Derrida [Entrevistado]; Anne Dufourmanelle; tradução de Antônio Romane; Revisão técnica de Paulo Ottoni. São Paulo: Escuta, 2003.

DEWEY, John. Arte como experiência. São Paulo: Martins Fontes, 2010. 
HALL, Stuart. Quem precisa da identidade?. In: SILVA, Tomaz Tadeu da (Org.). Identidade e diferença: a perspectiva dos estudos culturais. 15. ed. Petrópolis, RJ: Vozes, 2014.

HARAWAY, Donna. Saberes localizados: a questão da ciência para o feminismo e o privilégio da perspectiva parcial. Cadernos Pagu, (5), 1995:07-42.

FOUCAULT, Michel. Vigiar e Punir: nascimento da prisão. 42. ed. Petrópolis, RJ: Vozes, 2014.

LOPES, Alice Casimiro. Normatividade e intervenção política: em defesa de um investimento Radical. In: LOPES, Alice Casimiro; MENDONÇA, Daniel de. A Teoria do Discurso de Ernesto Laclau. Ensaios Críticos e Entrevistas. São Paulo: Annablume, 2016.

LOPES, Alice; MACEDO, Elizabeth. Teorias de Currículo. São Paulo: Cortez, 2011.

MACEDO, Elizabeth. A teoria do currículo e o futuro monstro. In: LOPES, Alice Casimiro; SISCAR, Marcos. Pensar política com Derrida: Responsabilidade, tradução, porvir. São Paulo: Cortez Editora, 2018.

MACEDO, Elizabeth. Mas a escola não tem que ensinar? Currículo sem Fronteiras, v. 17, n. 3, p. 539-554, set. 2017.

MBEMBE, Achille. Sair da grande noite: ensaio sobre a África descolonializada. Trad: Fábio Ribeiro. Petrópolis, RJ: Vozes, 2019.

MISKOLCI, Richard. A Teoria Queer e a Sociologia: o desafio de uma analítica da normalização. Sociologias, Porto Alegre, ano 11, nº 21, jan./jun. 2009, p. 150-182.

PAGÈS, Claire; TRACHMAN, Mathieu. Uma analítica do poder - Conversa com Judith Butler. Investigação Filosófica: vol. 5, n. 1, artigo digital 6, 2013.

PELÚCIO, Larissa; DUQUE, Tiago. Cancelando o cuier. Contemporânea, vol. 10, n. 1, p. 125-151, jan.-abr., 2020.

PEREIRA, Amilcar Araujo. Black lives matter nos currículos? Imprensa negra e antirracismo em perspectiva transnacional. Caderno de Pesquisa. São Paulo, v. 49 n. 172 p. 122-14, 2019.

RANNIERY, Thiago. Manifesto Beyoncé no currículo: a força da música e o brilho erótico do corpo que dança. In: PARAÍSO, Marlucy A.; CALDEIRA, Maria Carolina. Pesquisas sobre currículos, gêneros e sexualidades. Belo Horizonte: Mazza Edições, 2018. p. 199218.

SCHWARCZ, Lilia. Filme de Beyoncé erra ao glamorizar negritude com estampa de oncinha. Folha de São Paulo, São Paulo, 2 de agosto de 2020. Disponível em:

$<$ https://www1.folha.uol.com.br/ilustrada/2020/08/filme-de-beyonce-erra-aoglamorizarnegritude-com-estampa-de-oncinha.shtml>. Acesso em: 12 ago. 2020.

SILVA, Tomaz Tadeu da. Documentos de Identidade: uma introdução às teorias do currículo. Belo Horizonte: Autêntica, 1999. 
SODRÉ, Muniz . Pensar nagô. Rio de Janeiro: Vozes, 2017. 238 p.

VIVEIROS DE CASTRO, Eduardo. O medo dos outros. Revista de Antropologia, São Paulo v. 54 n. 2., 2011. p. 885-917.

YORK, Sara Wagner. TIA, VOCÊ É HOMEM? Trans da/na educação: Des(a)fiando e ocupando os "cistemas" de Pós-Graduação. Dissertação (Mestrado em Educação) - Faculdade de Educação, Universidade do Estado do Rio de Janeiro, Rio de Janeiro, 2020.

YOUNG, Michael. Currículo do Futuro. Campinas: Papirus, 2000. 